
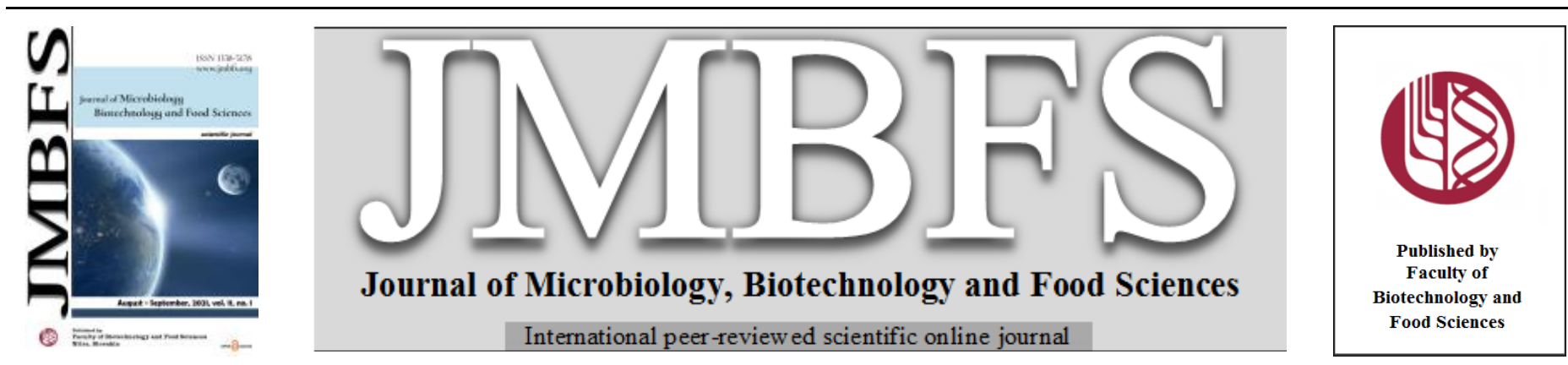

\title{
CONTROLLED FUNCTIONAL EXPRESSION OF THE CIRCULAR BACTERIOCIN ENTEROCIN NKR-5-3B AND THE LEADERLESS BACTERIOCIN LACTICIN Q
}

\author{
Rodney H. Perez ${ }^{1}$, Shun Iwatani ${ }^{2}$, and Takeshi Zendo ${ }^{2}$
}

Address(es):

${ }^{1}$ National Institute of Molecular Biology and Biotechnology (BIOTECH), University of the Philippines Los Baños (UPLB), College, Laguna 4031 Philippines, Tel. No.: +63(049)-536-2721.

${ }^{2}$ Laboratory of Microbial Technology, Division of Applied Molecular Microbiology and Biomass Chemistry, Department of Bioscience and Biotechnology, Faculty of Agriculture, Graduate School, Kyushu University, Fukuoka, Japan.

*Corresponding author: rhperez@up.edu.ph

https://doi.org/10.15414/jmbfs.4018

\section{ARTICLE INFO}

Received 30. 11. 2020

Revised 4. 2. 2021

Accepted 4. 2. 2021

Published 1. 8. 2021

Regular article

open ${ }_{\text {ACCESS }}$

\begin{abstract}
Bacteriocins are antimicrobial peptides that possess a number of desirable properties that can be utilized for application in various industries including the food and pharmaceutical industries. Enterocin NKR-5-3B (Ent53B) and lacticin Q (LnqQ) are well characterized bacteriocins that exhibit exceptional stability and potent antimicrobial activity. Here we report the establishment of a dualplasmid expression system of these bacteriocins by exploiting the quorum sensing production system of nisin known as the nisin inducible controlled expression (NICE ${ }^{\mathrm{TM}}$ ) system. Using this dual-plasmid expression system, the production of Ent53B and LnqQ can be controlled by the addition of exogenous nisin at sub-lethal concentration, either in pure or crude form, to induce the transcription of the genes responsible for the production of these bacteriocins. Using this system, cheap cultivation media instead of the commonly used complex and expensive cultivation media, can be utilized in the production of these bacteriocins thereby significantly lowering the production cost - one of the major limiting factors for its large-scale application. Additionally, this system provides a robust control of bacteriocin production thereby creating an effective bacteriocin application delivery system.
\end{abstract}

Keywords: lactic acid bacteria, bacteriocins, controlled bacteriocin expression, dual-plasmid expression

\section{INTRODUCTION}

Bacteriocins are antimicrobial peptides produced by diverse bacterial strains as primary metabolites in order for them to gain advantage in their ecological niche (Perez et al., 2014, Klaenhammer, 1993). Bacteriocin production among lactic acid bacteria (LAB) is considered a desirable trait especially to those strains involved in food fermentations. LAB bacteriocins are considered food-grade antimicrobials that can be utilized in addressing microbial contamination problems in foods that usually results to food spoilage and food-related infections (Cotter et al., 2005, Perez et al., 2015). Aside from being food-grade, LAB bacteriocins are ideal choice as food preservatives based on numerous aspects. Bacteriocins are inherently tolerant to higher thermal stress and are more active at a wider $\mathrm{pH}$ range common in many food systems. These bacteriocins are also colorless, odorless, and tasteless thus their application in food does not affect the food's sensory qualities (Perez et al., 2015).

It has long been established that bacteriocin production is a result of a coordinated expression of several genes controlled by the so-called quorum sensing-gene expression (Klaenhammer, 1993, Kuipers et al., 1998). Quorum sensing-gene expression involves specific molecules that act as signals for the induction of gene expression when a certain threshold concentration of the signal molecule has been reached (Kuipers et al., 1998). These specific signal molecules are either the bacteriocin itself or a bacteriocin-like peptide. Thus far, it has been proven that in the case of class I bacteriocins (lantibiotics), the bacteriocin itself acts as the inducing factor regulating the transcription of its own structure gene and the neighboring genes related to its biosynthesis (Kuipers $\boldsymbol{e t}$ al., 1995, Kleerebezem et al., 1997). In the case of non-lantibiotic bacteriocins (class II bacteriocins) bacteriocin-like peptides have been found to induce the expression of cognate biosynthetic genes (Kleerebezem et al., 2001, Ishibashi et al., 2014, Ennahar et al., 2000). The most characterized regulation system of bacteriocin production is the case of nisin biosynthesis. The auto-regulation of nisin biosynthesis is controlled by a two-component system consisting of the response regulator NisR (van der Meer $\boldsymbol{e t}$ al., 1993) and the sensor protein, histidine kinase NisK (Engelke et al., 1994). The sub-inhibitory amounts of extracellular nisin is transduced by autophosphorylation of NisR and subsequent phospho-transfer to NisR, triggering the transcription of the genes under the control of nisA and nisF promoters (de Ruyter et al., 1996a). As application to this quorum sensing expression system of nisin biosynthesis, a nisin-inducible expression system (NICE ${ }^{\mathrm{TM}}$ system) has been developed (de Ruyter et al., 1996b). The NICE ${ }^{\mathrm{TM}}$ system requires three essential elements: (1) a Grampositive host strain that expresses the nisRK genes; (2) nisin or nisin analogs as inducer molecule; and (3) plasmid vector containing the nisA or nisF promoter fragments.

Meanwhile, there has been a spike in the number of newly reported bacteriocins possessing varying characteristics and bioactivities during the last two or three decades. We recently reported two novel bacteriocins possessing exceptional properties that could be of high industrial relevance, the bacteriocins enterocin NKR-5-3B (Ent53B) and lacticin Q (LnqQ). Ent53B is a novel circular bacteriocin that is ultra-stable and possesses a broad spectrum bioactivity (Himeno et al., 2015), whereas LnqQ is novel leaderless bacteriocin with a very potent bioactivity that is higher than that of nisin, through a novel mode of action known as huge-toroidal pore (HTP) mechanism (Yoneyama et al., 2009). Moreover, the respective genetic elements responsible for the production of these bacteriocins have already been identified. The gene cluster composed of the genes enkB1, enkB2, enkB3, and enkB4 encodes the biosynthetic enzymes that works cooperatively to process the Ent53B precursor peptide, encoded by the gene enkB, producing its mature form (Perez et al., 2016). Whereas the biosynthetic enzymes responsible for the production of LnqQ are encoded in a gene cluster composed of the five genes $\ln q B C D E F$. These enzymes provide the secretion and self-immunity mechanisms of the producer strain to synthesize the LnqQ, which is encoded by the gene $\ln q Q$ (Iwatani et al., 2012).

In this present study, we report the establishment of a dual-plasmid heterologous expression system that offers a tight control of the production of Ent53B and LnqQ. Here we employed the NICE ${ }^{\mathrm{TM}}$ system that exploits the quorum-sensing regulation system of nisin biosynthesis, utilizing the nisin-inducible promoter to initiate the transcription of the respective structural genes of Ent53B and LnqQ. Here we highlight two main points: first is the capacity of this system to significantly lower bacteriocin production cost as it enables the recombinant strain to produce the bacteriocins Ent53B and LnqQ even in simple cultivation media which are relatively cheaper than the complex cultivation media commonly used in bacteriocin production. One of the main bottleneck hindering 
the industrial scale utilization of bacteriocins, particularly in the food industry, is its expensive nature of production (Cotter et al., 2005). The second point we highlight in this report is the capacity of this system to offer a tight control of bacteriocin production thereby improving the delivery of these novel bacteriocins. This controlled expression system serves as a virtual switch on-andoff of the bacteriocin production thereby providing control of an effective and timely delivery of Ent53B and LnqQ into the target application environment.

\section{MATERIAL AND METHODS}

\section{Bacterial strains and reagents}

The strains and plasmids used in establishment of the dual-plasmid expression system are summarized in Table 1. The host expression strain L. lactis NZ9000 was cultivated in M17 medium supplemented with $0.5 \%$ glucose (GM17) and grown at $30^{\circ} \mathrm{C}$. The indicator strains were cultivated in MRS medium (Oxoid, UK) and incubated at their respective optimum incubation conditions. Chloramphenicol $(\mathrm{Cm})$ and erythromycin $(\mathrm{Em})$ were used as antibiotic markers in selective media at a final concentration of $5 \mu \mathrm{g} / \mathrm{ml}$. All bacteria were stored at $-80^{\circ} \mathrm{C}$ in their respective media with $30 \%$ glycerol and cultivated twice before use.

Table 1 Bacterial strains and plasmids used in the dual-plasmid expression system

\begin{tabular}{|c|c|c|}
\hline Strain or plasmid & Description $^{a}$ & Reference or source $^{b}$ \\
\hline \multicolumn{3}{|l|}{ Strains } \\
\hline $\begin{array}{l}\text { Enterococcus faecium NKR-5- } \\
3\end{array}$ & Enterocin NKR-5-3B producer strain & Ishibashi et al., 2012 \\
\hline Lactococcus lactis QU5 & Lacticin Q producer strain & Fujita et al., 2007 \\
\hline L. lactis NZ9000 & Heterologous host strain, nisRK & de Ruyter et al., 1996b \\
\hline L. lactis NCDO 497 & Nisin A producer strain & $\mathrm{NCDO}$ \\
\hline \multicolumn{3}{|l|}{ Plasmids } \\
\hline pMG36c & $\begin{array}{l}\mathrm{Cm}^{\mathrm{r}} \text {, pWV01-based cloning vector carrying a strong lactococcal based } \\
\text { promoter } \mathrm{P}_{32} \text {, rolling-circle replication }\end{array}$ & Perez et al., 2016 \\
\hline pNK-B1234 & $\mathrm{Cm}^{\mathrm{r}}$, pMG36c derivative containing enkB, enkB1, enkB2, enkB3, and enkB4 & Perez et al., 2016 \\
\hline $\mathrm{pNK} \Delta \mathrm{B}$ & $\mathrm{Cm}^{\mathrm{r}}, \mathrm{pNK}-\mathrm{B} 1234 \Delta e n k B$ & This study \\
\hline $\mathrm{pNZ} \Delta \mathrm{B}$ & $\mathrm{Cm}^{\mathrm{r}}, \mathrm{pNK} \Delta \mathrm{B}$ derivative with nisin-inducible promoter, $\mathrm{P}_{\text {nis }}$ instead of $\mathrm{P}_{32}$ & This study \\
\hline pLNQ & $\mathrm{Cm}^{\mathrm{r}}, \mathrm{pMG} 36 \mathrm{c}$ derivative containing $\ln q B, \ln q C, \ln q D, \ln q E$, and $\ln q F$ & Iwatani et al., 2012 \\
\hline $\mathrm{pLNQ} \Delta \mathrm{Q}$ & $\mathrm{Cm}^{\mathrm{r}}, \mathrm{pLNQ} \Delta \ln q Q$ & This study \\
\hline $\mathrm{pLZ} \Delta \mathrm{Q}$ & $\mathrm{Cm}^{\mathrm{r}}$, pLNQ $\Delta \mathrm{Q}$ derivative with nisin-inducible promoter, $\mathrm{P}_{\text {nis }}$ instead of $\mathrm{P}_{32}$ & This study \\
\hline pIL-Pnis & $\mathrm{Em}^{\mathrm{r}}$, theta replicating vector, nisin-inducible promoter, $\mathrm{P}_{\text {nis }}$ & This study \\
\hline pIL-B & $\mathrm{Em}^{\mathrm{r}}, \mathrm{pIL}-\mathrm{Pnis}$ containing enkB & This study \\
\hline pIL-Q & $\mathrm{Em}^{\mathrm{r}}, \mathrm{pIL}-\mathrm{Pnis}$ containing $\ln q Q$ & This study \\
\hline
\end{tabular}

${ }^{a} \mathrm{Cm}^{\mathrm{r}}$, chloramphenicol resistant; $\mathrm{Em}^{\mathrm{r}}$, erythromycin resistant

${ }^{b}$ NCDO, National Collection of Food Bacteria, Reading, UK

\section{Construction of dual-plasmid expression system}

In order to construct a controllable dual-plasmid expression system of Ent53B and LnqQ, their respective structure genes were cloned into a theta-replicating vector, pIL-Pnis, that carry a nisin-inducible promoter, while the genes encoding their cognate biosynthetic enzymes were cloned into a rolling-circle replicating vector, pMG36c, that possess a strong constitutive promoter. These plasmids were introduced to L. lactis NZ9000, a nisRK expressing strain. To describe briefly, the respective structure genes of these two bacteriocins, enkB and $\ln q Q$ were PCR amplified using designed primers containing $N c o$ I and $X b a I$ restriction sites (Table 2) with the genomes of their respective host as template DNA during the PCR reaction. The amplified fragments were then separately digested with
$N c o$ I and $X b a \mathrm{I}$ and were individually ligated to the pIL-PnisA plasmid, which was previously digested with the same enzymes. The resulting plasmids were termed pIL-B and pIL-Q respectively. These plasmids were then introduced by electroporation into the host L. lactis NZ9000 previously transformed with the respective plasmid carrying the cognate biosynthetic genes, $\mathrm{pNKB} \Delta \mathrm{B}$ and pLNQ $\Delta$ Q. Construction of these plasmids was done by inverse PCR of the pNKB1234 and pLNQ plasmids, respectively. Briefly, outward facing primers were designed (Table 2) to generate a PCR product without the structure genes enkB and $\ln q Q$, respectively. The resulting PCR products were then phosphorylated using kinase enzyme (T4 polynucleotide kinase; Toyobo, Osaka, Japan) and subsequently self-ligated using Ligation High Ver.2 (Toyobo).

\begin{tabular}{llc}
\multicolumn{2}{l}{ Table 2 List of primers used to construct the dual-plasmid expression system } & \\
\hline Primer name & Sequence $\left(\mathbf{5}^{\prime} \rightarrow \mathbf{3}^{\prime}\right)^{a}$ & $\left.\mathbf{T m} \mathbf{(}^{\mathbf{0}} \mathbf{C}\right)$ \\
\hline NcoI-enkB-F & AAACCATGGATTCAGTGGTGGTAGTAACAG & $57^{b}$ \\
XbaI-enkB-R & AAATCTAGAGACCATGGCCAATTTATTCG & $57^{b}$ \\
NcoI-lnqQ-F & AAACCATGGGATTGTTGCAAAGAGAAAGCG & $61^{b}$ \\
XbaI-lnqQ-R & AAATCTAGAATACTAGTGAGATTATTGGC & $55^{b}$ \\
Inv(XbaI)-pIL-Pnis-F & CCACTAGTTCTAGAGAGCTCCG & 55 \\
Inv(NcoI)-pIL-Pnis-R & CATGCCTGCAGTACCCATGGTG & 59 \\
Inv-pNKB $\Delta$ B-F & CAGTCGCTACAATCATTGCT & 54 \\
Inv-pNKB $\Delta$ B-R & CTGTTACTACCACCACTGAATG & 53 \\
Inv-pLNQ $\Delta$ Q-F & AGATTGGCTTAATGCAGGTC & 54 \\
Inv-pLNQ $\Delta Q-R$ & TAACACGCTTTCTCTTTGC & 53 \\
pNis-F & CATTCTTTGCTGTAGATCTAGTC & 55 \\
pNis-R & TGCAGTACCCATGGTGAGTGCC & 55 \\
$\Delta$ P32-F & GCAGAAAAATTCGTAATTCGAGC & 58 \\
$\Delta \mathrm{P} 32-\mathrm{R}$ & CTAGTCCAAGCTCACAAAAATCC & 57 \\
\hline
\end{tabular}

${ }^{a}$ restriction enzyme sites are underlined.

${ }^{b} \mathrm{Tm}$, melting temperature at $0.1 \mathrm{nM}$ primer concentration

Induction of bacteriocin production and quantification of antimicrobial activity

The dual-plasmid expressing L. lactis NZ9000 strains were cultivated in $5 \mathrm{ml}$ GM17 liquid medium at $1 \%$ inoculation level and incubated at $30^{\circ} \mathrm{C}$. Antibiotic markers $\mathrm{Cm}$ and $\mathrm{Em}$ were added at final concentration of $5 \mu \mathrm{g} / \mathrm{ml}$ each. To induce the bacteriocin production, a nisin solution (either up to $10 \mathrm{ng} / \mathrm{ml}$ final concentration of commercial nisin A dissolved in $\mathrm{pH} 3.0$ water or a $500 \mu \mathrm{l}$ filtersterilized supernatant of the nisin producer strain L. lactis NCDO 497) was added to the culture after 2 hours of incubation and incubation was continued for at least 18 hours.

The antimicrobial activities of the recombinant strains were visualized and quantified using direct-colony overlay assay and spot-on-lawn assay respectively, as described previously (Perez et al., 2016). To briefly describe the direct-colony overlay assay, recombinant strains were pre-cultivated in $5 \mathrm{ml}$ GM17 medium containing antibiotic markers $(\mathrm{Cm}$ and Em) at $5 \mu \mathrm{g} / \mathrm{ml}$ each and incubated at $30^{\circ} \mathrm{C}$ overnight and sub-cultured into fresh medium containing the same antibiotic markers and kept under the same conditions for $24 \mathrm{~h}$. The number of cells of each recombinant strain was normalized to the same optical density 
$\left(\mathrm{OD}_{600}\right.$ of 3.0) using sterile distilled water. An aliquot of $1 \mu \mathrm{l}$ of the normalized cell solutions were then spotted onto a GM17 agar lawn inoculated with $1 \%$ indicator strain. After overnight incubation at $30^{\circ} \mathrm{C}$, inhibition zones around the colonies were examined to check for the production of the bacteriocins.

Whereas the spot-on-lawn assay was done by spotting $10 \mu \mathrm{l}$ of a 2 -fold serially diluted cell-free supernatant of the recombinant strains onto a double-layered agar plate, which contained $5 \mathrm{ml}$ of Lactobacilli Agar AOAC medium inoculated with an overnight culture of an indicator strain as the upper layer and $10 \mathrm{ml}$ of the MRS broth supplemented with $1.5 \%$ agar as the bottom layer. After an overnight incubation at $30^{\circ} \mathrm{C}$, the bacterial lawns were checked and inhibition zones measured. The activity titer expressed as arbitrary activity units (AU) was defined as the reciprocal of the highest dilution producing a clear zone of growth inhibition of the indicator strains.

\section{RNA isolation and semi-quantitative reverse transcription PCR (RT-PCR)}

Total RNA of each recombinant strain was extracted using the RNeasy kit (Qiagen, Germany) according to the manufacturer's instructions. Isolated RNA was treated with DNase I (Invitrogen, CA) to ensure the removal of residual DNA. The treated RNA was then used as templates for cDNA synthesis using SuperScript VILO ${ }^{\mathrm{TM}}$ cDNA synthesis kit (Invitrogen). The synthesized cDNAs were used as template for the RT-PCR to confirm the presence of the respective messenger RNA transcripts of $e n k B$ and $\ln q Q$. Concentration of the cDNAs were measured using NanoDrop ${ }^{\mathrm{TM}}$ spectrometer (Thermo Fisher Scientific) and were all normalized to $10 \mathrm{ng} / \mu \mathrm{l}$ by diluting with nuclease-free deionized water prior to the PCR reactions.

\section{Computer analysis of DNA sequence}

DNA samples were extracted from each recombinant strain using Exprep Plasmid SV minikit (GeneAll Biotechnology, Seoul, South Korea), submitted for DNA sequencing and were subsequently analyzed using the GENETYX-WIN software, version 8.0.1 (Genetyx, Tokyo, Japan).

\section{RESULTS AND DISCUSSION}

\section{Description of the Ent53B and LnqQ Dual-Plasmid Expression System}

The dual plasmid system that enables full expression control of Ent53B and LnqQ is based on the aforementioned NICE ${ }^{\mathrm{TM}}$ system. In this dual-plasmid expression system, the substrate (bacteriocin precursor peptide) is encoded in a separate plasmid from its catalytic enzymes (cognate biosynthetic enzymes). Here, the respective gene encoding the precursor peptides of Ent53B and LnqQ is cloned upstream the nisA promoter region of the theta-replicating plasmid pILPnis while the cognate biosynthetic gene cluster of these bacteriocins are encoded in a rolling-circle plasmid pMG36c carrying a constitutive promoter $\mathrm{P}_{32}$ (Fig. 1) The basis of choosing pIL-Pnis and pMG36c plasmids is their compatibility for dual-plasmid expression wherein they do not compete with each other for the replication machinery and do not compromise their plasmid copy numbers. These are critical factors that needs to be considered in developing recombinant protein expression systems (Rosano \& Ceccarelli, 2014). A subtle advantage in this dual-plasmid system we describe here is its relative amenability to genetic engineering wherein mutations can be easily introduced to the bacteriocin structure gene, e.g. to enhance the properties of the resulting recombinant bacteriocin, without risking the unnecessary introduction of mutations into the other genes involved in its biosynthesis that is located directly upstream of the original gene locus of the Ent53B (Perez et al., 2016) and LnqQ (Iwatani $\boldsymbol{e t}$ al., 2012) biosynthetic gene clusters

\section{Controlled Production of Ent53B and LnqQ}

The level of $e n k B$ and $\ln q Q$ expression and antimicrobial activity of the dualplasmid recombinant $L$. lactis NZ9000 expressing the pNKB $\triangle B$ ::pIL-B and pLNQ $\Delta$ Q::pIL-Q after exogenous nisin A induction showed in a concentration dependent manner (Fig. 2). The recombinants showed increasing strength of its inhibitory activity against the indicator strain as indicated with the increasing size of the zone of inhibition around the colony of the recombinants with increasing nisin A concentration added for induction. Whereas the same recombinant strains did not show any bioactivity in the absence nisin A (Fig. 2A). Moreover, the level of RNA transcription of the respective bacteriocin structure genes, enkB and $\ln q Q$, were upregulated with the corresponding increase of nisin A concentration, while no notable change of the level of transcription of the 16S rRNA of the recombinant strains (Fig. 2B). These results clearly show that this dual-plasmid system offers a tight control over the expression of these bacteriocins.
$\mathbf{A}$
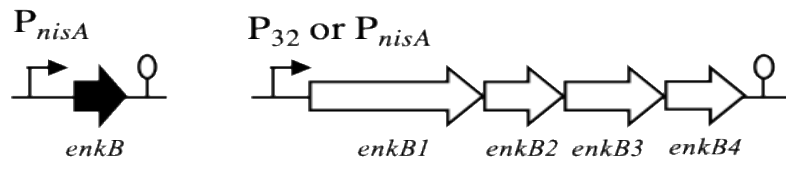

B

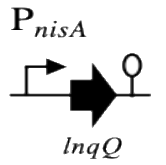

structural gene (pIL-P $\mathrm{P}_{\text {nisA }}$ )

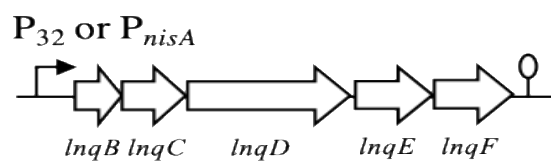

biosynthetic gene cluster (pMG36c or pMG-P ${ }_{\text {nisA }}$ )
Figure 1 Outline of the biosynthetic machinery of dual-plasmid expression system of enterocin NKR-5-3B and lacticin Q. Open arrows indicate the genes encoding the cognate biosynthetic enzymes of enterocin NKR-5-3B (A) and lacticin Q (B), respectively. These genes are encoded in a rolling-circle replicating vector, pMG36c, that possess a strong constitutive promoter $\mathrm{P}_{32}$ or a nisin-inducible promoter, $\mathrm{P}_{\text {nisA }}$. Black arrows represent the bacteriocin structural genes of enterocin NKR-5-3B (A) and lacticin Q (B), respectively, and are encoded in a theta-replicating vector, pIL- $\mathrm{P}_{\text {nisA. }}$. The bent arrows indicate the

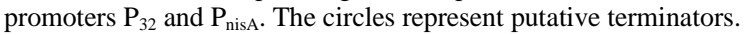

$\mathbf{A}$

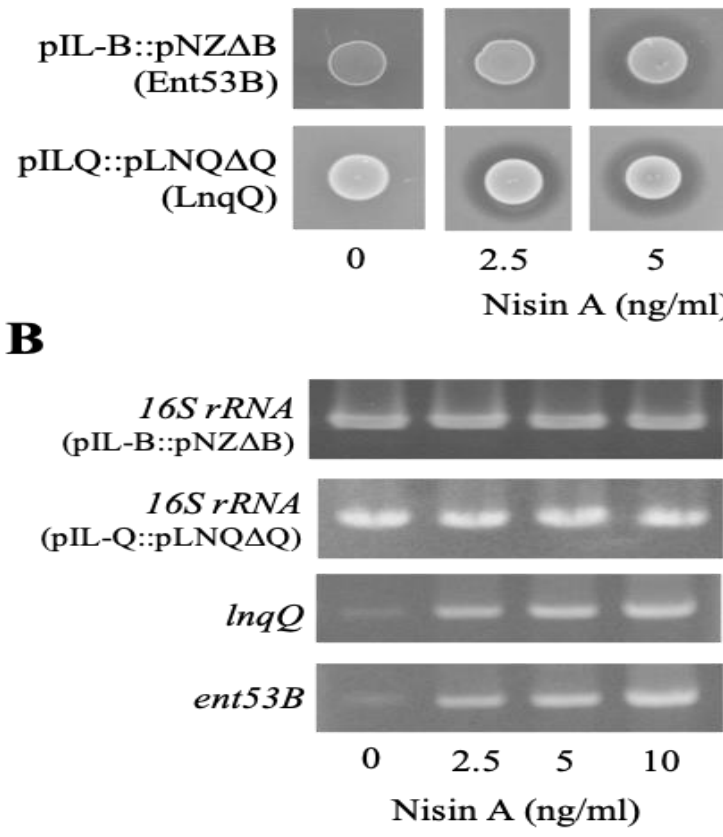

Figure 2. Concentration dependent nisin A-based induction of the expression of the biosynthetic genes of enterocin NKR-5-3B and lacticin Q. Bacteriocin production of Lactococcus lactis NZ9000 phenotypes carrying the dual-plasmid expression system, pIL-B::pNZ $\Delta B$ and pIL-Q::pLNQ $\Delta Q$ for the production of enterocin NKR-5-3B and lacticin $Q$, respectively showing concentration dependent enhancement of their bioactivities (A). The level of gene expression of the bacteriocin structural genes $\ln q Q$ and ent $53 B$ these recombinant strains showed concentration-dependent induction monitored using semi-quantitative reverse transcription PCR (RT-PCR) (B). The indicator strain used for the bioassay was L. lactis ATCC $19435^{\mathrm{T}}$ (nisin A minimum inhibitory concentration is $500 \mathrm{nM}$ ). The highest nisin A concentration used for the induction $10 \mathrm{ng} / \mathrm{ml}$ roughly equates to $3 \mathrm{nM}$.

To demonstrate the practical implication of this bacteriocin controllable production system, the recombinants were cultivated in a various media including a simple medium that is generally insufficient to support bacteriocin production. Without the addition of the inducing factor, nisin $\mathrm{A}$, the recombinants did not show any bacteriocin production even when cultivated at complex media such as MRS and GM17. Interestingly, the recombinants where able to produce the bacteriocins even when cultivated in a simple media TSBYE in the presence of the inducing factor either in pure form or from a crude culture supernatant of $L$ lactis NCDO 497, a known nisin A producer (Table 3). However, in TSBYE medium less enhancement of bacteriocin bioactivity was observed relative to other complex media MRS and GM17 (Table 3). This is probably because of the 
limited induction of the expression of the biosynthetic enzymes in TSBYE which may have acted as the limiting factor in bacteriocin biosynthesis. To circumvent this problem, the promoter region of the vector carrying the biosynthetic enzymes was changed to the nisin-inducible promoter Pnis to produce the $\mathrm{pNZ} \triangle \mathrm{B}$ and $\mathrm{pNZ} \Delta \mathrm{Q}$ shuttle vectors. Expectedly, the pIL-B::pNZ $\Delta \mathrm{B}$ and pIL-Q::pNZ $\Delta \mathrm{Q}$ expressing L. lactis NZ9000 strains manifested higher bacteriocin bioactivity even in less complex medium when induced with nisin (Table 3). This result presents a very high practical implication as it can significantly lower the bacteriocin production cost which is known to be a huge limiting factor for the large scale industrial application of bacteriocins (Cotter et al., 2005). Most LAB only produce bacteriocins when cultivated in complex cultivation media. It should be interesting to explore viable cheap feedstocks that can support the grow of these recombinants and by simply adding exogenous nisin A, such as that from the supernatant of strain NCDO 497, a potential economically feasible production system of these bacteriocins can be established.

Table 3 Nisin-induced production of Ent53B and LnqQ production in different medium

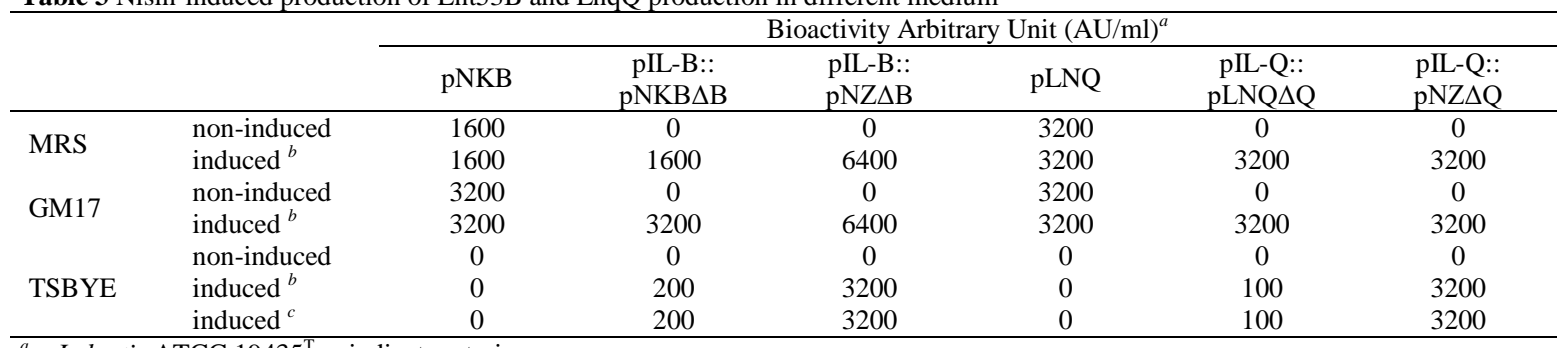

${ }^{a}-$ L. lactis ATCC $19435^{\mathrm{T}}$ as indicator strain

${ }^{b}$ - nisin A solution (Sigma-Aldrich)

${ }^{c}$ - supernatant of nisin A-producer L. lactis NCDO 497

Moreover, the virtual switch-on/switch-off capability of bacteriocin production of this dual-plasmid expression system offers a tight control of the delivery of bacteriocin in an actual application system, particularly in food fermentations. Food fermentations normally involves complex microbial flora, each distinctly contributes to the overall sensory and organoleptic characteristics of the food product including the production of compounds that contributes to the flavor and aroma of the food product. Whereas, bacteriocin producing strains has been utilized either as defined starter culture, adjunct, or protective culture in many food fermentations. Using the system we describe here, the recombinants can be introduced into the fermentation environment without affecting the other species, and once the fermentation is completed, bacteriocin production can be triggered by the addition of the inducing factor to ensure the stable quality of the food product. A similar work has been done in the acceleration of the ripening of cheese by utilizing a controlled expression of the lytic genes $l y t A$ and $l y t H$ that can trigger the lysis of cheese starter strain L. lactis thereby releasing the intracellular enzymes involved in flavor formation (deRuyter et al., 1997).

\section{Confirmation of Ent53B and LnqQ from the culture supernatant}

To confirm the identity of the heterologously synthesized Ent53B and LnqQ from the dual-plasmid recombinants, we purified the active fraction of the culture supernatants of these recombinants following the early reported purification system of these bacteriocins (Perez et al., 2016, Fujita et al., 2007). ESITOF/MS analysis of the purified Ent53B and LnqQ showed that both Ent53B and LnqQ showed several ions species with the quadruple charge ions as the most dominant. Computation of the molecular mass of these bacteriocins from the most dominant ion species showed identical to the previously reported molecular mass of the respective bacteriocins thus confirming their identity (Fig. 3).
$\mathbf{A}$

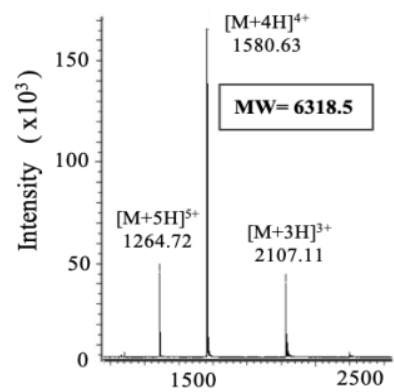

B

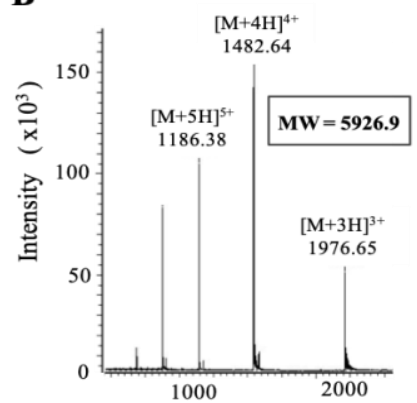

Figure 3 Electrospray ionization time-of-flight mass spectra of Ent53B (A) and LnqQ (B) isolated from culture supernatant of Lactococcus lactis NZ9000 phenotypes carrying the dual-plasmid expression system, pIL-B::pNZ $\Delta \mathrm{B}$ and pIL-Q::pLNQ $\Delta Q$ respectively. Detected multiple charge ions of Ent53B and LnqQ are indicated. Observed MWs of each bacteriocin is indicated in the inset of each panel. Observed MWs were calculated from the most abundant ion species which is the quadruple charged ions for both bacteriocins.

\section{CONCLUSION}

In the present study, we report the establishment of a controllable dual-plasmid expression system of the bacteriocins Ent53B and LnqQ using the NICE ${ }^{\mathrm{TM}}$ system. Here we showed that the activation of the bacteriocin genes, enkB and $\ln q Q$, expression through the induction of exogenous nisin $\mathrm{A}$ is highly robust which offers a rigid control in the production and delivery of Ent53B and LnqQ The highlighted practical implication of this developed system is its capacity to enable the recombinant strain to produce these bacteriocins even in simple and cheap cultivation media thus lowering the production cost of these bacteriocins.

Acknowledgements: We are grateful to the Japan Society for the Promotion of Science (JSPS) for providing a grant to Rodney H. Perez as a JSPS International Postdoctoral Fellow. We also thank Dr. Oscar Kuipers (Molecular Genetics Laboratory, Groningen University, the Netherlands) for providing the pIL- $\mathrm{P}_{\text {nis }}$ plasmid.

\section{REFERENCES}

Cotter, P.D., C. Hill \& R.P. Ross, (2005) Bacteriocins: developing innate immunity for food. Nature Reviews. Microbiology 3: 777-788. http://dx.doi.org/10.1038/nrmicro1273

de Ruyter, P.G., O.P. Kuipers, M.M. Beerthuyzen, I. van Alen-Boerrigter \& W.M. de Vos, (1996a) Functional analysis of promoters in the nisin gene cluster of Lactococcus lactis. Journal of Bacteriology 178: 3434-3439. http://dx.doi.org/10.1128/jb.178.12.3434-3439.1996

de Ruyter, P.G., O.P. Kuipers \& W.M. de Vos, (1996b) Controlled gene expression systems for Lactococcus lactis with the food-grade inducer nisin. Applied and Environmental Microbiology 62: 3662-3667. http://dx.doi.org/10.1128/AEM.62.10.3662-3667.1996

deRuyter, P.G.G.A., O.P. Kuipers, W.C. Meijer \& W.M. deVos, (1997) Foodgrade controlled lysis of Lactococcus lactis for accelerated cheese ripening. Nature Biotechnolology 15: 976-979. https://doi.org/10.1038/nbt1097-976

Engelke, G., Z. Gutowski-Eckel, P. Kiesau, K. Siegers, M. Hammelmann \& K.D. Entian, (1994) Regulation of nisin biosynthesis and immunity in Lactococcus lactis 6F3. Applied and Environmental Microbiology 60: 814-825. http://dx.doi.org/10.1128/AEM.60.3.814-825.1994

Ennahar, S., T. Sashihara, K. Sonomoto \& A. Ishizaki, (2000) Class IIa bacteriocins: biosynthesis, structure and activity. FEMS Microbiology Reviews 24: 85-106. http://dx.doi.org/10.1111/j.1574-6976.2000.tb00534.x

Fujita, K., S. Ichimasa, T. Zendo, S. Koga, F. Yoneyama, J. Nakayama \& K. Sonomoto, (2007) Structural analysis and characterization of lacticin Q, a novel bacteriocin belonging to a new family of unmodified bacteriocins of Grampositive bacteria. Applied and Environmental Microbiology 73: 2871-2877. http://dx.doi.org/10.1128/AEM.02286-06

Himeno, K., K.J. Rosengren, T. Inoue, R.H. Perez, M.L. Colgrave, K. Fujita, N. Ishibashi, T. Zendo, P. Wilaipun, V. Leelawatcharamas, H. Jikuya, D.J. Craik \& K. Sonomoto, (2015) Identification, characterization, and the three-dimensional structure of the novel circular bacteriocin, enterocin NKR-5-3B, from Enterococcus faecium. Biochemistry $\quad \mathbf{5 4}$ 4863-4876. http://dx.doi.org/10.1021/acs.biochem.5b00196

Ishibashi, N., K. Himeno, K. Fujita, Y. Masuda, R.H. Perez, T. Zendo, P. Wilaipun, V. Leelawatcharamas, J. Nakayama \& K. Sonomoto, (2012) Purification and characterization of multiple bacteriocins and an inducing peptide produced by Enterococcus faecium NKR-5-3 from Thai fermented fish

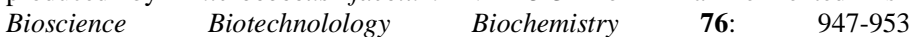
http://dx.doi.org/10.1271/bbb.110972

Ishibashi, N., K. Himeno, Y. Masuda, R.H. Perez, S. Iwatani, T. Zendo, P. Wilaipun, V. Leelawatcharamas, J. Nakayama \& K. Sonomoto, (2014) Gene cluster responsible for secretion of and immunity to multiple bacteriocins, the 
NKR-5-3 enterocins. Applied and Environmental Microbiology 80: 6647-6655. http://dx.doi.org/10.1128/AEM.02312-14

Iwatani, S., F. Yoneyama, S. Miyashita, T. Zendo, J. Nakayama \& K. Sonomoto, (2012) Identification of the genes involved in the secretion and self-immunity of lacticin Q, an unmodified leaderless bacteriocin from Lactococcus lactis QU 5. Microbiology 158: 2927-2935. http://dx.doi.org/10.1099/mic.0.062943-0

Klaenhammer, T.R., (1993) Genetics of bacteriocins produced by lactic acid bacteria. FEMS Microbiology Reviews 12: 39-85. http://dx.doi.org/10.1111/j.1574-6976.1993.tb00012.x

Kleerebezem, M., O.P. Kuipers, W.M. de Vos, M.E. Stiles \& L.E. Quadri, (2001) A two-component signal-transduction cascade in Carnobacterium piscicola LV17B: two signaling peptides and one sensor-transmitter. Peptides 22: 15971601. http://dx.doi.org/10.1016/s0196-9781(01)00494-6

Kleerebezem, M., L.E. Quadri, O.P. Kuipers \& W.M. de Vos, (1997) Quorum sensing by peptide pheromones and two-component signal-transduction systems in Gram-positive bacteria. Molecular Microbiology 24: 895-904. http://dx.doi.org/10.1046/j.1365-2958.1997.4251782.x

Kuipers, O.P., M.M. Beerthuyzen, P.G. de Ruyter, E.J. Luesink \& W.M. de Vos, (1995) Autoregulation of nisin biosynthesis in Lactococcus lactis by signal transduction. Journal of Biological Chemistry 270: 27299-27304. http://dx.doi.org/10.1074/jbc.270.45.27299

Kuipers, O.P., P.G.G.A. de Ruyter, M. Kleerebezem \& W.M. de Vos, (1998)

Quorum Sensing-controlled gene expression in lactic acid bacteria. Journal of Biotechnology 64: 15-21. https://doi.org/10.1016/S0168-1656(98)00100-X

Perez, R.H., N. Ishibashi, T. Inoue, K. Himeno, Y. Masuda, N. Sawa, T. Zendo, P. Wilaipun, V. Leelawatcharamas, J. Nakayama \& K. Sonomoto, (2016) Functional analysis of the genes involved in the biosynthesis of enterocin NKR5-3B, a novel circular bacteriocin. Journal of Bacteriology 198: 291-300. http://dx.doi.org/10.1128/JB.00692-15

Perez, R.H., M.T. Perez \& F. Elegado, (2015) Bacteriocins from lactic acid bacteria: A review of biosynthesis, mode of action, fermentative production, uses and prospects. International Journal of Philippine Science and Technology 8: 6167. http://dx.doi.org/10.18191/2015-08-2-027

Perez, R.H., T. Zendo \& K. Sonomoto, (2014) Novel bacteriocins from lactic acid bacteria (LAB): various structrures and applications. Microbial Cell Factories 13: (Suppl 1):S3. http://dx.doi.org/10.1186/1475-2859-13-S1-S3

Rosano, G.L. \& E.A. Ceccarelli, (2014) Recombinant protein expression in Escherichia coli: advances and challenges. Frontiers Microbiology 5: 172. http://dx.doi.org/10.3389/fmicb.2014.00172

van der Meer, J.R., J. Polman, M.M. Beerthuyzen, R.J. Siezen, O.P. Kuipers \& W.M. De Vos, (1993) Characterization of the Lactococcus lactis nisin A operon genes nisP, encoding a subtilisin-like serine protease involved in precursor processing, and nisR, encoding a regulatory protein involved in nisin biosynthesis. Journal of Bacteriology 175: 2578-2588 http://dx.doi.org/10.1128/jb.175.9.2578-2588.1993

Yoneyama, F., Y. Imura, K. Ohno, T. Zendo, J. Nakayama, K. Matsuzaki \& K. Sonomoto, (2009) Peptide-lipid huge toroidal pore, a new antimicrobial mechanism mediated by a lactococcal bacteriocin, lacticin Q. Antimicrobial Agents and Chemotherapy 53: 3211-3217. http://dx.doi.org/10.1128/AAC.0020909 